\title{
Sample acidification effects on carbon and nitrogen stable isotope ratios of macrofauna from a Zostera noltii bed
}

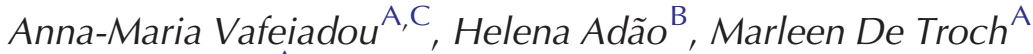 \\ and Tom Moens ${ }^{\mathrm{A}}$ \\ ${ }^{A}$ Ghent University, Marine Biology Section, Department of Biology, Krijgslaan 281/ S8, \\ 9000 Ghent, Belgium. \\ B University of Évora, School of Sciences and Technology, Biology, CO- CIEMAR c/o NemaLab, \\ Apartado 94, 7002-554 Évora, Portugal. \\ ${ }^{\mathrm{C}}$ Corresponding author. Email: am.vafeiadou@gmail.com
}

\begin{abstract}
Acidification treatment has been used in most stable isotope studies to eliminate inorganic non-dietary carbon, allowing $\delta^{13} \mathrm{C}$ measurement of organic carbon needed for trophic studies. Because only limited information about the acidification effects on isotopic ratios exists in the literature, we provide an assessment of such effects for a wide range of benthic macroinvertebrates from estuarine intertidal sediments with sparse Zostera noltii Hornem. vegetation. Our results revealed only few significant $\delta^{13} \mathrm{C}$ shifts for macrobenthos; however, $\delta^{13} \mathrm{C}$ decrease after acidification was substantial for several species. We conclude that acidification is not necessary for removing calcium carbonate in a majority of macrobenthos, but we also suggest preliminary testing before deciding it can be omitted. The magnitude of the $\delta^{15} \mathrm{~N}$ shifts was substantial for some species and variability in $\delta^{15} \mathrm{~N}$ values of replicate acidified samples exceeded that of nonacidified samples. Therefore, sample acidification should be avoided for $\delta^{15} \mathrm{~N}$ determination. Moreover, acidification effects vary considerably among species belonging to a single class, rendering generalisations from single-species information potentially spurious.
\end{abstract}

Additional keywords: decarbonation, inorganic carbon, macrobenthos, sample treatment, seagrass.

Received 26 June 2012, accepted 4 April 2013, published online 21 June 2013

\section{Introduction}

Stable isotopes have been used in many studies dealing with food-web analysis and trophic interactions (see review by Boecklen et al. 2011). Among others, stable carbon and nitrogen isotope analyses are widely used in aquatic food-web studies, giving information about both the utilisation of the food resources and the trophic level of the consumers (Peterson and Fry 1987).

Many studies have already investigated the effects of samplepreparation procedures on stable isotope ratios, mainly focusing on preservation methods (e.g. Bosley and Wainright 1999; Ryba and Burgess 2002; Sarakinos et al. 2002; Barrow et al. 2008) and the acidification of samples (e.g. Bunn et al. 1995; Jacob et al. 2005; Søreide et al. 2006; Ng et al. 2007; Jaschinski et al. 2008; Kolasinski et al. 2008; Mateo et al. 2008; Serrano et al. 2008). The latter is crucial for a correct analysis of tissue carbon isotopic composition because it removes inorganic, non-dietary carbon present in, for instance, shells. Calcium carbonate $\left(\mathrm{CaCO}_{3}\right)$ is the main source of inorganic carbon in most organisms and is highly enriched in ${ }^{13} \mathrm{C}$ compared with organic carbon, because of differences between organic matter synthesis and calcium carbonate precipitation (Craig 1953; DeNiro and Epstein 1978; Kennedy et al. 2005). Acidification of the samples with dilute $\mathrm{HCl}$ before isotope analysis has been widely used to eliminate $\mathrm{CaCO}_{3}$, so as to increase the accuracy of diet analysis. The use of $\mathrm{HCl}$ also leads to the formation of $\mathrm{CaCl}_{2}$, a hygroscopic compound which rapidly integrates water, potentially hampering accurate weighing and evaluation of $\% \mathrm{C}$ and $\% \mathrm{~N}$ of the samples; however, $\delta^{13} \mathrm{C}$ and $\delta{ }^{15} \mathrm{~N}$ measurement does not necessarily require determination of sample mass and $\% \mathrm{C}$ and $\% \mathrm{~N}$.

There is evidence that sample acidification may also affect nitrogen isotopic composition. Because carbonates do not contain nitrogen, a loss of organic ${ }^{15} \mathrm{~N}$ is assumed to be a result of acidification, attributed to small losses of acid-soluble proteins and amino acids via the volatilisation of oxidised nitrogenous organic compounds (Goering et al. 1990; Bunn et al. 1995). Nevertheless, different studies have produced highly equivocal results on the direction and magnitude of the acidification effect on $\delta^{15} \mathrm{~N}$ signatures. For instance, $\delta^{15} \mathrm{~N}$ increase as a result of sample acidification has been reported for penaeid shrimps (Bunn et al. 1995), fish (Bunn et al. 1995; Pinnegar and Polunin 1999), bivalves (Yokoyama et al. 2005), octopus (Carabel et al. 2006), Arctic crustaceans (Søreide et al. 2006) and tropical brachyurans (Kolasinski et al. 2008). In contrast, decreases in $\delta^{15} \mathrm{~N}$ were observed for blue crabs (Fantle et al. 1999), ghost 